\title{
LOS NIÑOS DE GALDÓS
}

La estructura familiar que es una constante de los argumentos galdosianos, su interés en poner de relieve la factibilidad de los caracteres heredados en adaptación o transgresión con el medio ambiente, han hecho copiosos los niños entre sus personajes, en número mayor que en textos de sus colegas generacionales.

Excluyendo Marianela (1878) y El doctor Centeno (1883), o bien la primera serie de los Episodios nacionales (1873-1875), no suelen ser protagonistas, pero precisamente cuando actúan en segundo plano como partenaires del principal, se hace sentir su gravitación en los acontecimientos, y aun en las decisiones y personalidad de aquél. A veces son meros correlatos de sus padres (los Peces, los Bringas); otras, los simbolizan en tanto mediadores de su origen y destino (los Valentines de Torquemada, 1889-1895), o preparan y coadyuvan en las determinaciones que toman los adultos (Luisito en Miau, 1888; Ción en Ángel Guerra, 1891). En casos aislados sus vidas individuales se distancian del conjunto funcionando de manera ejemplar y autónoma (Marianela, Felipín Centeno) o, acaso, su estado agónico confirma la sospecha de un orden ulterior, sobrenatural, y su influjo en el transcurrir humano (así, Ción, Valentín I, Monina en La familia de León Roch, 1878).

Instrumentos de Dios o reflejo de los hombres, Galdós abre en su novela, a través de los niños, una dimensión complementaria o contradictoria, según las situaciones, de las anécdotas centrales, que complejizan su interpretación para brindar un muestrario más amplio de la realidad social. 


\section{Promoción y ocaso del pícaro}

Como se sabe, el pícaro es el primer héroe del capitalismo, donde circulan bienes y personas, igualados en su común estándar de productos de mercado. Galdós apela a un lector implicito (Iser 1987) afincado en la memoria de la tradición literaria hispánica toda vez que consuma la experiencia vital de un adolescente en trance de cruzar al mundo adulto mediante la sola fuerza de su ingenio y pujanza, dentro de un hábitat severamente delimitado por leyes de acomodo económico, en las que prima la soltura en conseguir dinero y posición sin referencia obligada a talento o méritos.

En cambio, el horizonte de expectativas (Jauss 1978) del receptor respecto de la obra puede ser reconducido si, como en El doctor Centeno, el rapazuelo no obedece en su psicología a la ortodoxia del género, de la que se esperaba un cínico trepador inescrupuloso exento de caridad hacia el prójimo. Galdós manipula en forma alternativa el hipotexto clásico y reenvía al niño humilde por senderos de laboriosidad honesta menos previsibles.

El talante genético ya se adivinaba en Marianela afín al canon naturalista y en concordancia con el planteo parental de la picaresca: la niña huérfana; su madre, soltera de mísera condición y suicida; raquitismo, rostro feo y aspecto retardado: " $\mathrm{DDiez}$ y seis años! Atrasadilla estás, hija. Tu cuerpo es de doce, a lo sumo" (t. 1, p. 790)1. Una biografía que prepararía un prontuario. En Marianela, sin embargo, se desdice pronto el destino infalible de depravación física y ética. Se trata de un folletín-cuento infantil, y hasta su final trágico se endereza en esa dirección. Pero está ausente la distribución maniquea de malos y buenos según su clase, y en la "prima rica" Josefina se plasman perfecciones de belleza y altruísmo cristiano combinados que anticipan a la marquesa de Halma (1895), mejorando el modelo de la propia Marianela. La novela cumple a medias el ritual de fábula rosa (que apropiaría el teleteatro latinoamericano o culebrón después de la paraliteratura de cordel), visto y considerando la recuperación de la emetropía en "el señorito Pablo" antes ciego (nero ọue no se casará, esta vez, con la bondadosa cenicienta poco agraciada). Tampoco se verifica íntegramente el diseño experimental: Marianela debía suicidarse siguiendo el destino materno, pero el médico Golfín le impedirá el único acto libre de su vida cosificada — como si el na-

${ }^{1}$ Cito por las Obras (novelas), 3 ts., Aguilar, Madrid, 1980-1982-1986. 
turalismo se mordiera la cola: la decisión que rompería las leyes de descendencia sería idealmente la que las ratifica.

Una difusa muerte, "meningitis fulminante", o "de celos, de despecho, de amor contrariado. ¡Singular patología!" (t. 1, p. 773), cierra el círculo del feuilleton posromántico y justifica la exégesis de Casalduero: Marianela la imaginación, Pablo el racionalismo, Golfín la ciencia ${ }^{2}$. Sí ronda en la escritura darwiniana un cámpo semántico de proletarización minera que reifica o animaliza a las criaturas, en un continuum de la naturaleza cuyas fronteras entre reinos tienden a disolverse merced a la sistemática alienación que prefigura el maquinismo. Marianela, por dar un ejemplo, "duerme como una alhaja"' (t. 1, p. 713) en la vivienda de los capataces, pero allí “su jerarquía... era inferior a la del gato" y "todo le demostraba su semejanza con un canto rodado" (t. 1, p. 716) ${ }^{3}$.

Para subrayar su cuestionamiento de la desesperanza zolesca, Galdós provee a sus textos de hipotéticas pedagogías, como en $L a$ desheradada (1881), o resuelve la narración pronosticando aventuras constructivas de otro "hijo del pueblo" en Marianela:

Despidámonos para siempre de esta tumba... Volvamos los ojos hacia otro lado; busquemos a otro ser, rebusquémosle, porque es $\tan$ chico que apenas se ve; es un insecto imperceptible... Al fin le vemos; allí está, pequeño, atomístico. Pero tiene alientos y logrará ser grande. Oíd su historia, que no carece de interés (t. 1, p. 775).

Entonces abre el paréntesis de León Roch y examina el fracaso de una educación matrimonial, cuando ésta se deteriora en dos intolerancias el maestro de clase media y la mojigata noble en descenso, y luego reinaugura la misma dialéctica pero desenvolviéndola entre generaciones y en otra relación de dependencia: Centeno alumno sucesivo de la escuela institucional (Pedro Polo) y de la escuela vital (Alejandro Miquis).

El niño cambia de amos sin cambiar de conducta. Galdós había establecido en Marianela al picaro positivo, rebelde contra su familia y aldea, pero no resentido, lleno de fe en sí mismo pero no insolidario. Varias veces lo somete a pruebas que desmienten

${ }^{2}$ Casalduero 1943, p. 60.

${ }^{3} \mathrm{El}$ método de animalizar rasgos humanos es tópico en los naturalistas. La crítica galdosiana lo trató algunas veces. Ejemplos: KREBS 1967, pp. 6267; Paradissis 1971, pp. 133-142; Gilman 1985, pp. 289-299. 
el temperamento de outsider: puede odiar y no odia, puede traicionar a sus padres adoptivos y se resigna, puede robar y no roba, y como lo vemos en Tormento (1884) impide que su ama se envenene trocando el frasco nocivo que ella iba a ingerir para autoeliminarse, por uno inocuo; a su ínfima presencia se deberá la felicidad de Milagros. La ambición progresista desplaza a la codicia que delatase a los Lázaros y Buscones del siglo áureo. Además, Centeno desea ser médico como lo es Golfín; paradigma de héroe liberal-individual, su vocación se expresa en una profesión liberal ${ }^{4}$.

Pero nos hallamos ante una sociedad de arribistas. Celipín rompe la chatura quietista de su linaje - "la familia de piedra" la tildaba Galdós (t. 1, p. 712) - y huye a Madrid con la finalidad de ser "hombre de pesquis"' (t. 1, p. 714), mientras al filo de la Primera República y durante el comienzo de la Restauración, Mariano Rufete, "Pecado", sigue un periplo delictivo, aunque fuera de la demencia paterna y de la autoidealización nobiliaria de su hermana. Es su sincretismo: neurosis destructiva más rencor social (La desheredada). Isidora busca su identidad y Mariano la pierde: es el negativo de Celipín y pudiendo elegir entre opciones de distinto signo, optará por la criminal. Su última aparición lo dibuja con timas más negras que las de sus antepasados literarios, ya que hasta intenta el asesinato político y saborea la egolatría del magnicida: "'la idea de que todo el mundo se ocuparía de él... le embriagaba, le hacía reír con cierto modo diabólico y jactancioso" (t. 1, p. 1167) y unas líneas antes piensa que "la Nación en masa. . . la Sociedad entera estaba confabulada contra él", así que habrá de "castigar a la Sociedad, o al menos vengarse de ella'. Resentimiento, perversidad, una epilepsia que refleja su trastorno interior, el pícaro industrial encuentra demasiadas dificultades a su paso y está privado de paciencia tanto como del cinismo del triunfador. De cualquier manera siguen válidos los medios para destacarse, sólo eso cuenta, y si no

4 " El héroe adquirió al final la madurez que se hallaba inherente en su trayectoria formativa de aventuras. Felipín se vio libre, sin embargo, de la degradación que es característica de los héroes picarescos... fue salvado gracias a su visión optimista de la vida y a sus cualidades de bondad ingénita, humildad, sentimiento de compasión, gratitud, lealtad y paciencia en la adversidad" (Correa 1977, p. 260). Con respecto al otro antipícaro galdosiano, Gabriel Araceli (Episodios nacionales, primera serie), estos caracteres se acentúan, funcionando como parodia del Buscón de Quevedo (cf. Gutiérrez DíazBERNARDO 1991, pp. 73-81). 
hay lugar junto a los astutos (Melchorito, Sánchez Botín) quizá imite a los violentos (Gaitica, el pícaro ruin pero afortunado junto a quien, a su turno, termina Isidora antes de "suicidarse"). " "Valientes perdularios!" (t. 1, p. 1157)

Galdós deja una puerta abierta a través de otro niño, el huérfano Riquín (hijo de Isidora), que en mános de la próspera Emilia podrá redimir a su madre y tío, los Ícaros de "alas postizas" (t. 1, p. 1181). Como cree el narrador, la educación encauza, no en vano $L a$ desheredada finaliza con esa tangencial promesa de la nueva tutora: "En mí tendrás la madre que te falta".

\section{Los niños burgueses: Bringas y Peces}

Cuando la burguesía se cristaliza las excepciones empiezan a ralear, porque la clase media en pugna por ascender no se parece a la ya plenipotenciaria. Ahora, los hijos viven con sus padres, no se independizan de ellos ni gozan de una orfandad que los conduzca a una corrupción relativa o a una autonomía indemne más o menos perdurable. La familia se llama clan y conforma una suerte de feudo administrativo o comercial, bajo el mismo techo en arborización infinita gracias a matrimonios de casta: el diagrama más elocuente llega a ser el Arnáiz-Santa Cruz y al autor le basta apodar Delfines a'Jacinta/Juanito para designar a los vástagos de la nueva nobleza asentada. Los hijos heredan dinero antes que psicologías y es la sociedad en que se mueven quien los moldea a sus necesidades ecológicas de duración. Anhelan y logran la despreocupación, el rentismo, abolir el azar que hacía temeraria la vida de Felipe.

Galdós menudea en diminutivos al describir a los hijos de Pez, aunque ya casi abandonan la adolescencia; así, reduce irónicamente sus malandanzas, muy propias de jóvenes sobrecriados que atrasan su desarrollo debido al bienestar: todo lo contrario de Centeno o Pecado, a los cuales se empeña en tratar como mimadultos, adelantados por la lupa de la experiencia forzada.

De Adolfito, el "precoz funcionario" (t. 1, p. 1055) que "no

${ }^{5}$ Galdós subraya la maldad del nuevo pícaro convirtiéndolo en verdugo de su antepasado literario (t. 1, p. 1026). " ¿Cómo explicar el asesinato de Zarapicos por Pecado sino como una victoria de la cruda brutalidad naturalista sobre la suave y humorística revisión cervantina del género picaresco?" (GIL. MAN 1985, p. 121). 
iba a la oficina sino cuando le daba la gana", se dice lo mismo que de Luis, "iba nuestro galán centauro a la oficina lo menos que podía”' (t. 1, p. 1056) y de Antoñito: “Empleaba las horas de oficina en hacer revistas musicales para un periódico de teatros" (id.) y, del primero, se admira sarcástico: "¡Genialidad infantil que anuncia el embrión del hombre de Estado español!" (t. 1, p. 1055) al narrar una primeriza trapisonda contra el fisco: "¿Qué rasgo de genio! ¡Tú irás muy lejos, niño!, le dijo el jefe de negociado". A éstos se suma Federico, que

.. se había distinguido en esos círculos de sabiduría donde centenares de ángeles juegan al discurso. Era oradorcito... Primero hablaba y luego gritaba. Ensordecía los pasillos. Llegó a envanecerse de su facilidad de palabra... Hubo de volverse loco porque le dijeron que aún mamaba. ¡Disparate! Él no mamaba sino del presupuesto (t. 2, pp. 1055-1056).

Tal vez la sociedad empleomaníaca y congreseril yace enferma de puerilidad, y en las Cortes se "juega al discurso como en las covachuelas se juega al burócrata".

"No miremos con indiferencia el retoñar de los caracteres humanos en estos bosquejos de personas que llamamos niños"' advierte el involucrado narrador de La de Bringas (1884), "ellos son nuestras premisas; nosotros, ¿qué somos sino sus consecuencias?" (t. 2, p. 203). La frase encuadra una declaración de principios para los hijos de "Thiers" y Rosalía, que actúan en un segundo plano pero igualmente duplican a las claras los vicios de sus progenitores.

Poco se dice de Paquito, si bien lo enlaza a la ictiología de los Peces: "Sin esperar que... se hiciera licenciado en dos o tres Derechos, habíale adjudicado un empleíllo de Hacienda con 5.000 realetes, lo que no es mal principio de carrera burocrática a los diez y seis años mal cumplidos", faena que no le deparaba extremosos sacrificios: "No ponía los pies en la oficina más que para cobrar los 416 reales y pico que le regalábamos cada mes por su linda cara' (t. 2, p. 128); Manuel Pez, invencible paladín de los despachos, es su padrino laboral y el tercer lado del triángulo "amoroso"' en la novela.

Más se explaya Galdós sobre los otros dos niños. A Isabelita la presenta como achacosa crónica, de pésimas digestiones y epileptoide - la epilepsia, suprema patología galdosiana, ya afloraba en Mariano, dijimos, y vuelta metáfora animista se le aplica- 
ba a la prensa mecánica que manejara aquél con Juan Bou: "Tenía quejidos de herido y convulsiones de epiléptico" (t. 1, p. 1099). Amén de constituir una denuncia oblicua acerca de la frecuencia de niños enfermizos en la España decimonónica (muchos de los galdosianos lo son), transportados al seno de la clase media simbolizan en lo fisiológico las profundas lacras morales que anidan en ella. El metabolismo de Isabel, que vomita cuanto come, explicita la imposibilidad de crecer, una "inanición opulenta' adecuada a la situación inestable de su familia bajo amenaza de extinción. Torquemada morirá de indigestión; Isabelita, hija de otro avaro (la zoología taxonómica de la novela habla del "ratoncito Pérez") sufre de no digerir. También el nombre es arquetipo del sujeto: el ideal imitativo de Rosalía la bautizó como la reina en eclipse. Padece sueños premonitorios ${ }^{6}$ a semejanza de Luisito (Miau, 1888), mas el "río de sangre"' (t. 2, p. 190) de la Revolución jacobina no se produce; en realidad proyecta en su subconsciente escenas de desavenencia conyugal de sus padres que ha, inopinadamente, entrevisto. "Todo lo tenía ella en sí misma, cual si se hubiera tragado medio mundo"' (t. 2, p. 191). Nacen de su atascado estómago más que de la controvertida espiritualidad que coronará a Luis Cadalso-Villaamil.

Los juegos infantiles ponen de manifiesto hasta qué punto los niños Bringas reiteran a sus padres y recalcan sus defectos. Alfonsín gusta de derrumbar columnas de objetos diversos amontonados sin orden; de nuevo la destrucción al lado del consumismo, en lugar de regurgitar el alimento despedaza muebles en pila, y se entusiasma con el tráfico de las mudanzas, que son las parcas de toda ruptura del sistema. Una versión lúdica del cenotafio que Bringas urde con resabios de muertos y cuya perdurabilidad nada puede garantizar.

Isabelita, a falta de comida, acumula "cuanta baratija inútil caía en sus manos"' (t. 2, p. 203) y comenta a su padre "yo salgo a ti... guardo todos los cuartos que me dan"' (t. 2, p. 181). Y en efecto, este Thiers que no recuerda al verdadero Thiers ${ }^{7}$, ahorra vanamente en una época orientada a la circulación de divisas, pero aceptemos asimismo que el acopio ciego de fruslerías, la "manía coleccionista"' (t. 2, p. 203) alude a Rosalía y su pa-

${ }^{6}$ Cf. Schraibman 1960.

7 VAREY 1966 informa que el apodo "Thiers" es irónico, ya que la actitud acumulativa de Francisco Bringas se opone al liberalismo de Louis-Adolphe Thiers, que preconiza la circulación monetaria. 
sión por los mozambique, pelo de cabra, fichú, aigrettes, piqué, que a corto o mediano plazo colmarán su guardarropa. Isabel es, pues, un símbolo doblemente dirigido. Viste y desnuda alternativamente muñecas de porcelana (t. 2, pp. 137-138) y su mamá llama luego al esposo "muñeco" con desprecio (t. 2, p. 180); ambos, marido y mujer, son marionetas en virtud del fingimiento hipócrita (nunca sabremos si su invidencia es fisiológica o simple coartada para la abulia moral) del primero y de las veleidades de la segunda, maniquí viviente que extenúa las finanzas domésticas comprando, para después venderse. Cosificación que emblematiza, por un lado, la frivolidad misma del país monárquico y por otro, con su cosecha objetual, una locura extra: la fiebre adquisitiva del capitalismo. "Siguen los cacharritos... No pongamos los botones de hueso al lado de los de metal; separemos igualmente los de hueso de los de madera, no sea que riñan. En todas partes hay clases, hija mía"' (t. 2, p. 203) ${ }^{8}$.

En los Episodios nacionales, los niños se localizan en el coro del escenario histórico, anónimos y colectivos, y en un flanco que les consiente teatralizar los hechos que conciernen, teóricamente, a los seres maduros. En La desheredada los veíamos remedar a Prim y a O'Donnell en sus inocentes juegos de guerra callejera que, por intromisión del desenfrenado Pecado desembocarán en un asesinato, probablemente como los auténticos planes políticos que, bien intencionados en una fase preliminar epilogan en catástrofes, alegoría de la muerte de las utopías: “¡Ilusión de los hijos del Pueblo en los primeros albores de la ambición, cuando los instintos de gloria comienzan a despuntar en el alma, entre el torpe balbucir de la lengua...!"' (t. 1, p. 1040). Los mismos juegos resurgen en el episodio Prim (1906), con los hijos de Ibero, que representan los tres estratos residuales del poder en España: Santiaguito, soldado; Fernando "cortadito para la carrera eclesiástica" (Episodios, t. 3, p. 537) y la niña Demetria, díscola y emancipada, otra versión de la reina Isabel. En La de los tristes destinos (1907) Santiago Jr. y Vicentito Halconero miman la profesión de varios agonistas de las series: son "inocentes historiadores": "El uno era la Historia libresca; el otro, la Historia vivida, ambos incipientes, balbucientes, en la época de la dentición" (ibid., p. 657), y no es extraño que Santiaguito extrapole

${ }^{8}$ Cf. Round 1971, pp. 43-50.

${ }^{9}$ Para las citas de los Episodios me baso en la siguiente edición: Episodios nacionales, 3 ts., Aguilar, Madrid, 1941. 
la Conquista de México por Hernán Cortés a la turbia intervención de Prim sobre la nación azteca, como si se verificase el aserto marxista según el cual todo acaece dos veces, una vez como tragedia y otra como farsa. El juego, como oarábola final, se repetirá en Amadeo I (1910): en Las Peñuclas, los infantes juegan "al pronunciamiento": "Los ideales exaltados son ahora instintos movidos por la imbecilidad"' (ibid., p. 1073). La impostura de este devenir hispánico estrangulado de futuro debiera desengañar a Mariclío, la musa satirizada de la Historia (o la musa de la Historia satirizada) mentora y cicerone del historiador Tito Liviano: los chicos forman batallones y recomponen a los personajes públicos del pasado, Prim, Napoleón, el Empecinado - como si Galdós se parodiara a sí mismo, a través de los héroes que titularon sus novelas anteriores- y al pasar la diosa y su discípulo, los apedrean sin miramientos. Módica revancha de hijos contra padres, o de ciudadanos imberbes hacia aquellos que debieron conferirles mejor posteridad (ibid., p. 1039).

\section{Los emisarios divinos: Luisín, Valentines, Pitusos...}

Existen también personajes infantiles que ofrecen un espejo al presente de sus mayores, y hay quienes ofician de puente a su futuro. Aquí nunca se parecen a sus padres, cualquiera fuese su estamento social; como catalizadores de resoluciones fundamentales en sus vidas, son funcionales y providenciales, y obran develando un sentido oculto del plan universal o hacen posible en sus padres o allegados decisiones que cambiarán la fisonomía moral de éstos.

El primer matrimonio estéril que afronta Galdós es el de León Roch y María Egipcíaca, estéril no como resultado de una infertilidad física sino desde la incompatibilidad ideológica, tan inconciliable que los esposos seguirán caminos individuales, y María se encastilla en el hermetismo místico mientras León busca fuera del marco familiar comprensión e indulgencia. Roch se convierte entonces en virtual padre adoptivo de la hija de Pepa Fúcar, Monina, cuyo padre carnal boga muerto o prófugo después de sonados fraudes financieros. El cuadro general de España, así expuesto, es tétrico: el krausista extemporáneo y solitario, la esposa beata e intransigente, la marquesita rica e infeliz y, victorioso en la cúspide, el estafador intacto, Cimarra.

En este contexto se enferma Monina, de un mal otra vez 
símbolo, el crup que entorpece la respiración: la asfixia esperable en una sociedad sin libertad, prejuiciosa, " uno de los más crueles ejemplos del dolor inexorable que acompaña, como prueba o castigo, a la vida humana" (t. 1, p. 856). El crup suscita una agonía tan torturadora que hace más patética la impotencia de los hombres y por ende, reconoce la participación divina, que sería desgarradora si ella misma no salvara a la niña. El médico Moreno Rubio, un Golfín desconcertado, confiesa: "No he sido yo, señora; ha sido la Naturaleza, el tártaro y la disolución cáustica... en una palabra: la Naturaleza sola, o, mejor dicho, Dios solo" (t. 1, p. 861). León, el racionalista, cuando "no era dueño de sí mismo, rezó por la cura en el instante en que estaba moribunda: «Señor, que no se muera Monina. ¡Es lo único que amo en el mundo!»" (t. 1, p. 860). Mediante esta aparente concesión, Galdós humaniza a su filósofo impasible; Monina es el instrumento que despertará en él sentimientos religiosos, de una religión natural brotada del dolor. León, en fin, no era ateo o lo fue hasta entonces, cuando resucitó a una suerte de erasmismo: el milagro rompe la rigidez kantiana y confirma la fe genuina, "todo el que llama con fevor y humildad será oído" (t. 1, p. 860$)^{10}$.

Para Fortunata, el sueño folletinesco de Marianela tampoco será posible, pero en la novela aldeana podía culparse a la fatalidad, esa que encegueció a Pablo y desfiguró a su lazarillo. En cambio, en la novela urbana el rigor de los destinos personales depende de la tectónica social misma, dividida de manera inmutable y sin posibilidad alguna de intercambio institucionalizado en el tema amoroso y en su dinámica interna. Marianela ha crecido después de muerta y se trasladó a Madrid, donde a trueque de su desaliño físico perdió la honradez: Fortunata.

Claro que se nota una relajación de las leyes naturalistas. De la niña de Socartes conocíamos a sus padres, según su testimonio, y leíamos cierto condicionamiento raigal de penuria insuperable. Fortunata viene mitificada por relatos de terceros; se filtra primero a través de los recuerdos de Juanito como una "memoria de ambiente", y en la primera parte de Fortunata y Jacinta sólo vemos de ella el coto de su educación: su tía Segunda, Ido del Sagrario y Nicanora, José Izquierdo. El milieu es decisivo y Juan, con sus juicios absolutos sobre el "pueblo" aplasta desde el comienzo su estatuto de existencia al inmovilismo y la inferioridad.

${ }^{10}$ Pérez Gutiérrez 1975, p. 230. 
Del mismo modo, los dos Pitusos del texto tipifican el medio más que una discutible paternidad.

Como si salieran de una commedia dantesa con sus escalones de réprobos, los "pequeñuelos" del bajo fondo madrileño entre quienes zumba el primero "no podían pertenecer a la raza humana, y con aquel maldito tizne extendido y rebosando por la cara semejaban micos, diablillos o engendros infernales" (t. 2, p. 536). Una vez que lo distinguimos del conjunto, se dice de él que "tenía... el aspecto de un bicho muy malo que se comía a la gente" (t. 2, p. 539): otra vez el bestiario darwiniano pero ahora sube una categoría en la negatividad: no lo subhumano del animal sino lo sobrehumano inquietante del ser satánico. Luego se describe su conducta revoltosa y los atracos y demoliciones que perpetra en casa de los Delfines. Es sintomático que robe las velas que adornan el Nacimiento ("la primera manifestación que hizo de sus ideas acerca de la libertad humana y de la propiedad colectiva consistió en meter mano a las velas de colores", t. 2, p. 570) y, a continuación, decapita las siluetas del pesebre (t. 2, p. 573): el "salvajito" esconde un perfecto Anticristo en miniatura, cuyo Señor del Averno-suburbio es Izquierdo-"Platón", "tú sirves... para modelo de pintores... Pues ellos te ponen vestido de Santo, o de caballero, o de Padre Eterno" lo alaba y se burla la "santa" Guillermina Pacheco (t. 2, p. 559). Añadamos que Galdós usa las vísperas de Navidad como recorte temporal donde situar imposibles resurrecciones de pícaros delicuentes ${ }^{11}$; recordemos los consejos y admoniciones de Isidora a Pecado en el final de la primera parte de La desheredada: "Ahora, señorito... ha de andar usted derecho. Pase que en otro tiempo ... ocurrieran ciertas... barbaridades... Echémosles una losa encima... Eres ya otra persona"' (t. 1, p. 1064). Acto seguido, el chico pignora a su hermana dos diamantes falsos (t. 1, p. 1070) y se edifica un liderato de granujas. No existe renacimiento moral pese a que nace el Niño en tal efemérides, como si nacieran también los ladrones, junto a los cuales aquél será crucificado.

El primer Pituso, desde ya, no contiene de infernal más que el insospechado (y efímero) descubrimiento de un orden diferente dentro del que congela el consuetudinario pasar de los Santa Cruz; como tal produce en las relaciones sociales una momentánea inversión que adelanta la que el segundo Pituso conseguirá

${ }^{11}$ Dendle 1980, pp. 24-25; Heard \& Rodríguez 1982, pp. 129-130. 
en un futuro ubicado fuera de la novela, en la nueva vida de Jacinta madre sustituta. Significa una revolución microscópica en el núcleo del clan burgués - la misma que no se efectivizará políticamente en la macrorrealidad nacional no obstante la ficción de la Gloriosa y sus posteriores y abortadas remezones, cuyos viejos atavismos tanto inflan el anecdotario de Izquierdo; no por nada la ironía galdosiana lo congela a él también como extático modelo de muralistas históricos. Por eso el Juanín ineducable es "hijo del pueblo" y no descediente corroborable de Fortunata y Juan. Su anonimia, enseguida desbaratada, resume nuevamente la receta experimental al clima de origen.

La burguesía mercantil, pues, padece un momento de Infierno y entretanto, la generosidad de Jacinta derrama un lapso paradisíaco en la barriada indigente. Pero este mundo al revés, ilusorio, se desvanece al comprobarse que es una fábula elucubrada por el folletinista Ido, quien suele delirar cuando sufre hambre. Folletín que sólo fortuitamente logra alterar el curso de las cosas, aunque el cruce de clases pervive a nivel discurso, como cuando el Pituso llama "putona" a Jacinta (t. 2, p. 552) y Adoración, hija de Mauricia La Dura, se encariña con la Delfina, "era como una idolatría el cariño de aquella chicuela" (t. 2, p. 560), un vaticinio de la confusión que tendrá Fortunata al llamar a Guillermina "La Dura" 12, certeza de que la novela rosa se cumplirá, pero vicaria y póstumamente para Fortunata, mediante la cesión del segundo Pituso bastardo a manos de Jacinta.

La influencia de Luisito en la familia Villaamil es más fuerte que la de ambos Pitusos en los Santa Cruz: de ser una consecuencia de las acciones, el personaje-niño pasa a ser causa.

Volvemos a conocer el movimiento del ghetto administrativo, pero sin la habilidad ministerial de los Peces, sino en la cesantía de una rama biológica nada exótica y desprestigiada, los Gatos. Se comprende que, pronta a bajar la clase media un peldaño social, vacilen sus miembros en la fe sobre la justicia divina, que amplía en escala la iniquidad humana, y que sea el serafín de los Miaus el interlocutor elegido por Dios para explicar sus desig-

12 "Es visible el diseño complementario (entre Guillermina y Mauricia), la polaridad de lo demoníaco y lo angélico, encarnado en dos personajes antagónicos, entre quienes no es difícil discernir una semejanza, y no solamente de función, sino de textura... Mauricia y Guillermina son seres humanos, contradictorios, equívocos; por eso la santa puede ser monstruosa y el demonio quiere llevarse a Dios consigo, "agasajándolo en mi seno»" (Gullón 1970, pp. 159-160). 
nios, si bien Su perfil y voz son atributo de los sueños infantiles de Luis. Tal vez el Dios de esta mesocracia crepuscular, respetuoso de la libertad de sus criaturas y sin embargo impotente para restringir sus actos, carezca de voluntarismo y sólo se arriesgue a constatar las decisiones de los que no recolocan a Don Ramón y tornan desdichada a Abelarda. Al mismo tiempo su aparición en una mente de niño señala al único privilegiado químicamente puro en el rebaño felino sin autoestima ni instintos de supervivencia.

Como todo emisario angélico, Luisito redunda en reacciones opuestas, siempre conectadas a su entidad ambigua diabólico/mesiánica. Que el demonio sea su propio padre, Víctor Cadalso, implanta otra ruptura de la continuidad naturalista, y las ideas consiguientes de sus familiares lo acercan o lo alejan de sendas concepciones. Abelarda siente repulsa y la ataca la epilepsia cuando su sobrino le sugiere que despose a Cadalso: "El pobre niño era un monstruo, un aborto del Infierno, venido a la tierra para castigo y condenación de la familia" y "el chiquillo aquel representaba toda la perfidia humana, la traición, la mentira, la deshonra, el perjurio"' (t. 2, p. 1082). Después, Luis refiere a su abuelo la impracticidad de sus esfuerzos para recuperar el puesto, "cuanto más pronto te vayas al Cielo, mejor"' (t. 2, p. 1107); "eran las palabras de su nieto como revelación divina, de irrefragable autenticidad" (id.). Antes, Villaamil había dicho: "Ese demonches de chiquillo sabe más que todos nosotros y que el mundo entero" (t. 2, o. 1054), y al despedirse de ese mismo mundo entero: "Adiós, chiquillo celestial; tu abuelito te bendice... mejor sería decirte que te pide la bendición, porque eres un santito" (t. 2, p. 1115). Luisín gravita incisivamente en padre e hija. Aun cuando el cesante no se suicida por "revelación divina" sino al término de una larga secuencia de frustraciones, el niño rubrica el punto final de su determinación, al diluciclarle ésta como una forma de resignación cristiana en torno a un orden trasterreno, aunque este orden certifique el absurdo de su vida. Abelarda no se casa con Víctor, y es el niño mismo instrumento de la feionía paterna cuando lo utiliza para zanjar una deuda ${ }^{13}$. Su influjo es negativo, ya que los dos Villaamil se suicidan por su mediación ${ }^{14}$, pero se adhiere coherente a su naturaleza bifronte, angé-

13 Ruano de la Haza 1984, p. 140.

14 SCANlon \& Jones 1971, p. 59. 
lica sin finalidad y demoníaca sin proponérselo, adecuada al terrible Dios de Miau.

Había dos Pitusos en Fortunata y Jacinta y hay dos Valentines en Torquemada: ambos textos establecen una paridad estructural en cuanto a la emergencia de sus niños. El primer Pituso atraviesa la primera parte de las "dos historias de casadas" y el segundo la cuarta; Valentín I es el llorado prodigio de Torquemada en la hoguera (1889), primera fracción de la serie total, y Valentín II es el no menos lamentado sobreviviente de la cuarta, Torquemada y San Pedro (1895): son los dos ángulos de sendos destinos, demarcan la frontera de los adultos en juego y realzan la sintomatología simbólica del rango social y personal de los protagonistas. Adjuntemos que la simetría con que Galdós redacta sus libros se recicla en su digitación de la muerte: doña Silvia, primera esposa del usurero, muere de cólico miserere, vomita sus excrementos; Torquemada morirá de indigestión, como si se repitieran los signos de gula crematística en defunciones que los castigan por "lo que se tragaron", las deyecciones que Silvia excreta por la boca (t. 2, p. 1339) concatenadas a la fiebre voraz del prestamista manducándose... judías (t. 2, p. 1600).

$Y$ si el hijo de la burguesía comercial y de la franja marginal pronostica (o propone) el advenimiento de una nueva clase, espiritual antes que económico-financiera, y por lo tanto la redención mediante la educación (Fortunata y Jacinta), la semilla de la aristocracia en declive junto a la burguesía parasitaria en ascenso será indicio del cretinismo ingénito de una peligrosamente malsana (Torquemada), caras de una moneda que, reunidas, siembran la esperanza demasiado cerca de la completa condenación. De nuevo se apela a un lenguaje premeditadamente religioso al lado de uno darwiniano. "Ese niño es cosa inexplicable. . . o tiene el diablo en el cuerpo o es el pedazo de divinidad más hermoso que ha caído en la tierra"' se dice del primer Valentín, y un presagio eucarístico: “Cuando este chico sea hombre asombrará y trastornará el mundo" (t. 2, p. 1343). Pero el portento de inteligencia y precocidad será arrebatado por la muerte; la equidad divina se presenta a través del niño ahora matándolo, como antes salvó a Monina en León Roch.

Y en magra compensación, dejará vivir incomprensiblemente a Valentín II, "caso teratológico" (t. 2, p. 1515), "muñeco híbrido" (p. 1522), "mamarracho" (p. 1558), "¡Demonio de engendro!" -casi igual que "engendro del demonio" (p. 1573), " "pobrecito fenómeno" que "no parecía hijo de hombre" sino un 
“terrible animalejo" (p. 1572), y sus símiles: corderillo (p. 1560), mono, cotorra (p. 1562), perro, cochino, burro, "bestia cazadora" (p. 1572), etc., que ninguna de las ingenuidades de su madre Fidela ("diamante en bruto", p. 1562, en quien "la travesura del animalillo anuncia la inteligencia del hombre", p. 1572) podrá conjurar: su cuna necesaria será "una pesebrera de oro" (p. 1584); la parodia del nacimiento de Cristo, y los calificativos que aluden a su doble naturaleza, pero volcadas sobre un Anticristo, se redoblan, como en el primer Pituso y en Mariano. Si Galdós pergeñó en los marqueses de San Eloy una dinastía de Austria burgueses, Valentinico II es su Carlos II el Hechizado. Esta costumbre de mostrar niños deformes proviene, por supuesto de la cepa naturalista ${ }^{15}$, pero Zola suele continuar el itinerario bio-cronológico de los sucesores de volumen en volumen, mientras el escritor español paraliza su evolución a la edad primera, lo que habilita su más insistente función de símbolo complejo: no importa tanto qué serán, sino de quiénes son y más todavía a qué clases, en sus recíprocas contaminaciones, retroyectan.

Pero además, el segundo Valentín es una recopilación de caracteres de todos los niños galdosianos: macrocefálico como Riquín, la hipertrofia del cráneo inversamente proporcional a su exiguo cerebro, sugiere un estigma de pretendidos aristócratasplebeyos o pequeño-burgueses (léase Saldeoro, San Eloy, Rufete-"Aransis"); recolector de chucherías inconducentes como Isabelita Bringas ("los criados que hacían la limpieza descubrían... grandes depósitos de cosas heterogéneas: botones, pedazos de lacre, llaves de reloi, puntas de cigarro, tarjetas... y pedazos de moldura arrancados a las doradas sillas", t. 2, p. 1560); destrozón sin remedio como Alfonsín o el primer Pituso. ¿Nos querrá decir Galdós que la adición de tales calamidades representa el futuro vivo de toda España? "iQué razones habrá tenido Dios para darles, como emblema del porvenir aquella triste y desconsoladora alimaña!"' (t. 2, p. 1560).

Claro que los hijos de Torquemada no inciden en su comportamiento; sólo lo instan a descreer de la ecuanimidad divina $-\mathrm{y}$ a intentar saldar sus cuentas impagas con Dios dado su exacerba-

15 BOUDREAU 1980, p. 124, cree que los niños de Torquemada "represent a symbolic pole of their father's materialism", es decir, "genius and savage -the numerical and the primitive". Y añade: "This latter view of inheritance fmds frequent expression in Zola's noveis in which the Macquart blood line produces abnormal types who may be either geniuses or depraved criminais. Varieties of this configuration are frequent in Galdós". 
do egocentrismo. A Rafael del Águila, el suicida, el segundo Valentín le descubre la pérdida de su jerarquía en la casa junto a la certidumbre de un orden inmanente detestable que ha de permanecer.

El caso de Ción, la hijita de Ángel Guerra, nutre al máximo la idea del niño transformador de sus padres, así como el inventor del dominismo fecunda la estirpe trunca de los Manso y Roch hacia el estilo perfeccionado de Nazarín: el rebelde ansía cambiar el mundo ya no por la pedagogía sino por el activismo, desde la clandestinidad organizada hasta la militancia evangélica. En este proceso gradual de metamorfosis interior, que lo propulsa a abdicar de la violencia para predicar el amor, Ángel tiene una aliada prioritaria, Leré, muchacha en quien Galdós puntualiza $a b$ ovo su propia superación del naturalismo, pues hija de un padre alcohólico y criada por un padrastro déspota en medio de un clima degradante, seguirá una senda semimonjil, reacción psicológica antes que moral a ese mismo entronque situacional. El autor no olvida, sin embargo, las dicotomías que postulara en los $\mathrm{Va}$ lentines cuando articula, como hermanos de Lorenza, a un genio musical sin rasgo de retardo mental y a "cuatro monstruos, no todos iguales, pues hubo otro totalmente sin piernas y otro con la cabeza deforme' (t. 3, p. 71). Leré, excepción, hace la regla. $\mathrm{Y}$ Galdós sintetiza en cada nueva novela a todas las anteriores mientras ensaya un nuevo y vigoroso argumento.

Pero quien verdaderamente ilumina a Ángel es su Ción, primero a través de su muerte, precedida de una agonía locuaz. A Leré se le aparecía la Virgen; Ción dice que el niño Jesús dejó una postal en su puerta. Guerra se subleva contra el orden divino: "Invocaba al cielo y a la tierra con clamores y reticencias airadas y groseras, como esos criminales empedernidos que blasfeman, escupen al cielo y forcejean en los peldaños del patíbulo" (t. 3, p. 88). Galdós pone en boca del "señor de Pez"' la réplica que lo hará abjurar de su rebelión, como si mediante los personajes de siempre se reinstaurara el ámbito que comúnmente origina grandes terremotos anímicos. “¿Crees tú que Dios Omnipotente, que castiga y premia, iba a dejar en tus manos a ese ángel, como recompensa de tus actos contra la moral, contra el orden social y la religión?', (id.). Parece una contradicción que sea Pez, el vituperable hombre público, pero en realidad su presencia es atinada, ya que tipifica el orden humano-institucional, inamovible, y puede entonces ser portavoz del orden Superior y trascendente. Amén de que el diagrama social que defiende y espeja Pez 
con su persona y dichos es aquel que aniquila físicamente a Guerra (los García Babel, otro clan Pez), aunque esta vez la obra del "sacerdote laico" persista más allá de su vida. Se nos ocurre que Ción es sufijo de palabras como Resurrcc-Ción, Transfigura-Ción o Revela-Ción, e inclusive puede inferirse una casuística bíbilica a través de los nombres (Pez, Babel): Ción se interpretaría así como Sión: el País o la Nación de Dios (la Ciudad de Dios agustiniana) que existe en todos los pueblos y naciones del orbe pero no tiene corporeidad en el tiempo ni en el espacio.

Ción morirá, pero luego Ángel tiene una visión en la Catedral de Toledo, en la cual la voz y el rostro de la niña le hablan:

Sin forzar su imaginación, el atribulado creyente oyó aquella graciosa y timbrada vocecilla como si fuera la de Ción, rasgando las nubes... para decirle: 'Papaíto, no te sometas, Leré es tuya, tan tuya en la religión como fuera de ella, y Dios hará lo que a ti te dé la gana'" (t. 3, p. 225).

La niña que moría para enseñarle el atajo incorrecto que tomara su pasado, le confia ahora lo inmejorable de su futuro. "Doña Leré del Toboso" (t. 3, p. 222) será en él su "esposa mística" (t. 3, p. 184): una nueva pareja adamita-quijotesca en la religión positiva que soñará con reeducar a la raza española ${ }^{16}$.

Finalmente, en los dos extremos del corpus galdosiano, Gloria (1876-1877) y El caballero encantado (1909), el hijo recién nacido de las parejas protagónicas (Gloria/Morton, Cintia/Tarsis) cierran cada relato como expectativas acariciables de ese país que los personajes luchan por entender y modificar.

\section{Los hujos de Galdós}

Hay diferencias de edades tanto como de ambientes sociales entre las tres categorías de niños galdosianos.

Los pícaros serían estudiantes primarios si alguna clase de educación escolarizada los acogiera o lograran adaptarse a sus cuadraturas. Galdós ultima detalles de su naturaleza y después los somete a pruebas: o bien eluden él colegio por su propio salvajismo de preadolescentes callejeros (Pecado) o lo resisten sufridamente hasta que su personalidad autónoma los empuja a 
desertar, precisamente para evitar el resentimiento (Centeno). Mariano es elemento negativo para la escuela, prefiriendo pertenecer a "los presidios sueltos del porvenir" (t. 1, p. 1071), mientras en el caso Felipe la escuela misma es elemento negativo. Luego la relación personaje/contexto se bifurca en biografías opuestas, y Centeno discrepará y se alejará de las imposiciones del medio, frente a Pecado que, proclive a corromperse, se inoculará en la vida circundante y se confundirá con ella. En ambas criaturas de ficción la psicología prima sobre el entorno.

En los niños burgueses se halla un punto medio: la educación en el circuito cerrado de la burocracia cenacular los revitaliza como émulos generacionales de sus padres. Su conducta mimética adjudica al escritor el modo de entablar una ligazón reflexiva directa sobre sus progenitores, de los que son sus símbolos. Aquí se insertan adolescentes y párvulos, y actúan según el ambiente.

Por último, los niños angélicos, con los que Dios o un Orden suprahumano premia o castiga a los adultos, son necesariamente inocentes, o sea de edad preescolar en su mayoría, sufragando una cierta virginidad mental que en el caso de Valentín I se lee como intelecto superdotado fuera de toda normalidad. Si en el primer modelo el niño no influía en el medio (Pecado lo hacía dolosamente) pero aquél maduraba (en la maduración maligna del maleante o en la caritativa del buen burgués), y en el segundo proseguía impertérrita una chatura familiar idéntica, en el tercero este influjo se revierte sobre los mayores alterando la direccionalidad de la educación y de las leyes genéticas. Por eso desaparecen los efectos formativos, climáticos o naturales en estos niños que, sujetos del pensamiento divino, no es posible comparar con nadie, nunca hijos de su tiempo sino de Galdós, o, mejor, de la Palabra.

Gabriel Cabrejas

Universidad Nacional de Mar del Plata

\section{BIBLIOGRAFÍA}

Boudreau, H. L. 1980. "The salvation of Torquemada: Determinism and indeterminacy in the later novels of Galdós", $A G, 15,113-128$.

Casalduero, Joaquín 1943. Vida y obra de Galdós. Losada, Buenos Aires.

Correa, G. 1977. "Galdós y la picaresca", CEG (1), 253-268. 
Dendee, B. J. 1980. "On the supposed "Naturalism» of Galdós' La desheredada", en Papers on Romance Literary Relations. Ed. Hugh H. Chapman. Pennsylvania State University, University Park, pp. 24-25.

Gilman, Stephen 1985. Galdos y el arte de la novela europea, 1867-1887. Taurus, Madrid.

Gullón, Ricardo 1970. Técnicas de Galdós. Taurus, Madrid.

Gutiérrez Díaz-Bernardo, E. 1991. "Gabriel Araceli como Pablos de Segovia, Ecos del Buscón en Trafalgar", Scriptura, 6/7, 73-81.

Heard, M., \& A. Rodríguez 1982. "La desesperanza de la Nochebuena: Larra y Galdós", $A G, 17,129-130$.

Iser, WolfGang 1987. El acto de leer. Taurus, Madrid.

Jauss, Hans Robert 1978. Pour une esthétique de la réception. Gallimard, Paris.

Krebs, ERnesto 1967. "Marianela" y "Doña Bárbara". Ensayo de comparación. Cuadernos del Sur, Bahía Blanca.

Paradissis, J. G. 1971. "La mezcla satírica de características humanas y animales en Miau, de Benito Pérez Galdós", BICC, 26, 133-142.

Pérez Gutiérrez, Francisco 1975. El problema religioso en la generación de 1868. Taurus, Madrid, pp. 181-267.

Round, N. 1971. "Rosalía Bringas' children", $A G, 6,43-50$.

Ruano de la HazA, J. M. 1984. "The role of Luisito in Miau", $A G, 19,27-43$.

Scanlon, G., \& R. O. Jones 1971. "Miau: Prelude to a reassessment", $A G$, $6,53-62$.

Schraibman, Joseph 1960. Dreams in the novels of Galdós. Hispanic Institute, New York.

Sopeña Ibáñez, Federico 1970. Arte y sociedad en Galdós. Gredos, Madrid.

VAREY, J. E. 1966. "Francisco Bringas, nuestro buen Thiers", $A G, 1,43-50$. 
